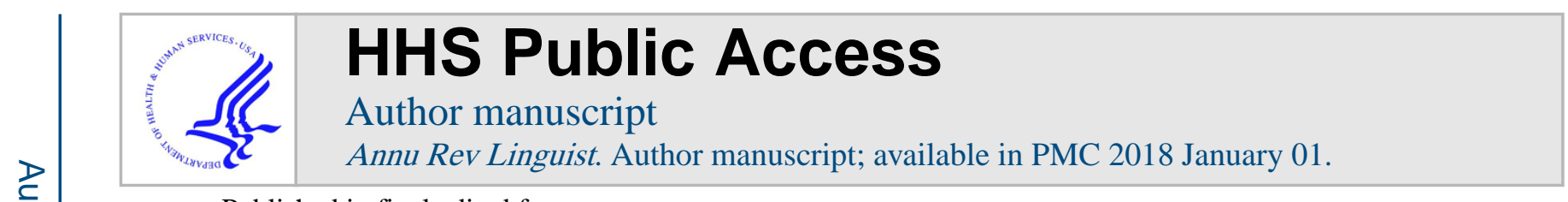

Published in final edited form as:

Annu Rev Linguist. 2017 ; 3: 363-388. doi:10.1146/annurev-linguistics-011415-040743.

\title{
Language Emergence
}

\section{Diane Brentari ${ }^{1}$ and Susan Goldin-Meadow ${ }^{2}$}

${ }^{1}$ Department of Linguistics, University of Chicago, Chicago, Illinois 60637

${ }^{2}$ Department of Psychology, University of Chicago, Chicago, Illinois 60637

\begin{abstract}
Language emergence describes moments in historical time when nonlinguistic systems become linguistic. Because language can be invented de novo in the manual modality, this offers insight into the emergence of language in ways that the oral modality cannot. Here we focus on homesign, gestures developed by deaf individuals who cannot acquire spoken language and have not been exposed to sign language. We contrast homesign with (a) gestures that hearing individuals produce when they speak, as these cospeech gestures are a potential source of input to homesigners, and $(b)$ established sign languages, as these codified systems display the linguistic structure that homesign has the potential to assume. We find that the manual modality takes on linguistic properties, even in the hands of a child not exposed to a language model. But it grows into full-blown language only with the support of a community that transmits the system to the next generation.
\end{abstract}

\section{Keywords}

gesture; homesign; sign languages

\section{INTRODUCTION}

Language emergence describes the crucial moments in historical time when a nonlinguistic system becomes a linguistic one. The properties of language involved, the order in which they appear, and the factors that facilitate their appearance are all important questions that need to be asked about language emergence. The term language emergence can refer to a variety of phylogenetic and ontogenetic situations-language evolution (Anderson 2004, Tomasello 2008), language acquisition (Lightfoot 1999, Newport 1999), or the creation of pidgins and creoles (DeGraff 1999, 2001). Spoken languages do not offer opportunities to directly address the central issues in language emergence, as these languages were first formed in the underdocumented recesses of history. As a result, language in the oral modality is not the best place to examine language emergence. The manual modality, by contrast, offers an in vivo laboratory in which we can observe how a language emerges in the absence of a prior language. Studies of language emergence in the manual modality thus

\footnotetext{
*A visual abstract of this article is also available online at https://www.youtube.com/watch?v=AJxcFLMe6Fc and as Supplemental Material.

DISCLOSURE STATEMENT

The authors are not aware of any affiliations, memberships, funding, or financial holdings that might be perceived as affecting the objectivity of this review.
} 
allow us to observe language creation de novo, unlike studies of language acquisition and language creolization, both of which are grounded in previously established languages. And studies of language emergence in the manual modality allow us to observe language creation in modern-day human creators, unlike studies of language evolution, which focus on creation in nonhuman primates. Here we take a perspective on language emergence that has gained attention within the last 30-40 years and that focuses on three types of communication within the manual modality: homesign, gesture, and sign language. ${ }^{1}$

Homesign is used by deaf individuals whose hearing loss prevents them from acquiring a spoken language, and who have not been exposed to a sign language. In addition, homesigners do not read or write the ambient spoken language because they do not regularly attend school, either because there is no school to attend or because of their young age. Under such inopportune circumstances, without a spoken or sign language model, these deaf individuals might be expected to fail to communicate altogether. This turns out not to be the case. Despite their impoverished language-learning conditions, deaf individuals not exposed to a signed or spoken language develop gestural communication systems, known as homesign systems, that contain many, but not all, of the properties of natural language (Goldin-Meadow 2003b). In the case discussed below, in Nicaragua, the homesign systems and an emerging sign language can be linked directly.

The gestures that hearing people produce when they talk offer a key comparison for homesign because we must determine whether a homesign system is an elaboration of the cospeech gesture systems used by the hearing people surrounding the deaf homesigner (family and acquaintances) or a system that is qualitatively different from cospeech gesture (i.e., a system that resembles sign language). Arguing that homesign is different from gesture presupposes that we know what gesture is. Both the gestures that accompany speech (cospeech gesture; Goldin-Meadow 2003a) and the gestures that are produced without speech in the laboratory when speakers are asked to communicate using only their hands (silent gesture; Goldin-Meadow et al. 1996) have been used as a comparative base for homesign. We know a great deal more today about gesture than we did when the first research on homesign appeared (Goldin-Meadow \& Feldman 1977). Kendon \& Cook (1969) and Kendon (1980) were some of the first authors to describe the meaningful function of gesture that accompanies speech, arguing that it is not simply hand-waving but rather adds important information to spoken utterances. McNeill $(1992,2000,2005)$ and his successors took this position much further and argued that the gesture-plus-speech utterance comprises what we think of as language. This literature provides an important point of departure for research on homesign.

In addition to comparing homesign with gesture, it is important to compare homesign with sign languages, some of which have been studied for several decades and have been found to be equivalent in complexity to their spoken language counterparts (Stokoe 1960, Stokoe et al. 1965, Frishberg 1975, Battison 1978, Klima \& Bellugi 1979, Supalla 1982, Padden 1988, Lucas \& Valli 1992). Some sign languages are several hundred years old [e.g., American

\footnotetext{
${ }^{1}$ The glosses and translations throughout the text are as indicated as follows: Italics are used for translations into English, single quotes for homesign glosses, and small caps for sign language glosses.
} 
Sign Language (ASL), British Sign Language (BSL), German Sign Language (DGS)], but they are nonetheless relatively young in comparison to spoken languages (Brentari 2010). The core community of sign language users is composed of deaf individuals with extensive hearing loss. Typically these individuals learn the ambient sign language from those around them-from members of their communities at school or at home. Sign language users of well-established sign languages are often bilingual in the sense that they read and write the ambient spoken language as well (e.g., English, German, Cantonese), although they are typically more comfortable and more proficient in their sign language.

Linguistic analyses of sign languages began in earnest during the same period as analyses of homesign and gesture, and we now know enough about sign language grammars to have a fairly clear picture of sign language as a point of arrival, so to speak; that is, we can see what homesign systems will become under conditions favorable to language emergence. In a typical language acquisition situation, the system is transmitted from one generation to another within a family setting, but in the case of a sign language, even an established one, the transmission often takes place outside of the family —in a school or wherever community members gather together.

In order to understand why the topic of language emergence has gained increasing visibility and importance within the last several years, consider the fact that all three areas have matured during roughly the same time period since the 1970s. As our understanding of each of these three types of manual systems has grown, the points of comparison for homesign have become more varied and more precise — on the one hand, comparisons with hearing people's gestures can provide insight into the input to homesign, and on the other hand, comparisons with sign languages can provide insight into the standard against which homesign can be evaluated.

Several factors can play a role in catalyzing a system to move toward becoming a fully fledged sign language (Goldin-Meadow 2010, Brentari \& Coppola 2013). First, the system may need to be used as the primary means of communication and thus bear the full burden of communication in order to take on linguistic structure (Goldin-Meadow et al. 1996). A lingua franca, such as Plains Indian Sign Language (Davis 2006), or cospeech gestures will not suffice. Second, a linguistic community may be crucial for individual users to experience the system not only as conveyers of information but also as receivers of information (GoldinMeadow et al. 2015a). This situation typically involves a group of people who use the same system and interact on a regular basis. Third, a language model may be essential; specifically, a system that is already in use by the linguistic community may be modified by newly entering members as they acquire and use the system (Senghas 2003, Coppola \& Senghas 2010). Populations with each of these factors have now been extensively studied and compared, providing evidence for a range of linguistic phenomena that do (and sometimes do not) depend on a language system (a) being the primary means of communication, (b) having a linguistic community, or (c) having a language model.

This article has three main sections. Section 2 summarizes the evidence showing that homesign (which bears the full burden of communication) contains linguistic structure and is thus qualitatively different from cospeech gesture (which does not bear the full burden of 
communication). Section 3 situates homesign within the context of established sign languages. Because we know that homesign systems are precursors to these languages, we can ask how far a single individual (a homesigner) can go toward having a fully functioning language without a linguistic community or a language model. Section 4 highlights the surprising findings revealed by this research thus far, namely how evidence from language emergence has confirmed, or called into question, some of the long-standing assumptions about language.

\section{HOMESIGN COMPARED WITH COSPEECH GESTURE}

\subsection{Are Homesign Systems Organized in the Same Way as Cospeech Gestures?}

Homesign systems function like language in many respects-they are used to make requests of others, to comment on the present and nonpresent, to make generic statements about classes of objects, to tell stories about real and imagined events, to talk to oneself, and to talk about language (Goldin-Meadow 2003b). The question we ask is whether homesign assumes the structure of language along with its linguistic functions.

Much of the original research on homesign focused on comparing homesign with cospeech gesture because it had to be determined whether homesigners were simply learning the gestures of their hearing caregivers. In order to explore the overlap in structure between homesign and cospeech gesture, the researchers compared the gesture combinations of homesigners with the gestures that their hearing parents produced when interacting with their deaf children. For each linguistic structure examined, homesigners' gestures differed from the cospeech gestures produced by the homesigners' hearing family members (GoldinMeadow \& Mylander 1983, 1984, 1998; Goldin-Meadow et al. 1994, 1995, 2007; Hunsicker \& Goldin-Meadow 2012; M. Flaherty, D. Hunsicker \& S. Goldin-Meadow, manuscript in preparation). For example, homesigners steadily increased their use of complex gesture sentences (a string of gestures expressing at least two propositions, e.g., a 'blow' gesture followed by a 'bubble-go' gesture, describing a bubble-blowing event) over time. In contrast, their hearing mothers did not use complex gesture sentences consistently until months after their children did, if at all (Figure 1) (Goldin-Meadow \& Mylander 1998). Thus, homesigners are not modeling their gestures after the cospeech gestures their hearing parents produce.

Why don't hearing parents display linguistic structure in the gestures that they produce with their deaf children? One possibility is that all of the gestures that the hearing parents produce when interacting with their deaf child are produced along with speech. Because gesture and speech form a single, integrated system (McNeill 1992, Goldin-Meadow 2003a), the cospeech gestures that the parents produce are not free to take on the structures found in homesign. To test this hypothesis, Goldin-Meadow et al. (1996) asked English speakers to describe a series of events in speech, and then to describe the events again, this time using only their hands. They compared whatever gestures the participants produced with speech during the first run-through with the "silent" gestures the participants produced when asked to use only their hands. The interesting result is that the gestures produced without speechthat is, the gestures that had to take on the full burden of communication-looked qualitatively different from the gestures produced with speech. In fact, they began to look 
like homesign (although, interestingly, they did not contain all of the properties found in homesign; see also Goldin-Meadow 2015). Homesign is not a simple elaboration of cospeech gesture, in large part because it must assume the full burden of communication. As such, homesign functions more like sign than like the gestures that accompany speech.

\subsection{Do Homesign Systems Show Linguistic Properties?}

Homesign systems contain a wide range of linguistic properties, called the resilient properties of language because they can be developed without input from a language model (Table 1) (Goldin-Meadow 2003b). Here we focus on a sample of the resilient properties found in the core areas of syntax and morphology, as well as prosody. The crucial point is that even though the gestures of homesigning children look transparently iconic-and, in fact, they must be transparent in order for the hearing people around them to understand what the gestures are communicating - the gestures have linguistic organization. Early research on homesign looked primarily at properties that were internal to the individual child's system. That research compared properties of homesign with those of child language learned from a model (Goldin-Meadow \& Mylander 1984) in order to demonstrate that there was, in fact, structure in homesign. It was only later that researchers began to compare homesign directly with well-established sign languages on the same levels of structure, and to assess it with the same statistical models used to determine whether any linguistic system has combinatorial structure (Goldin-Meadow \& Yang 2016).

2.2.1. Syntax: constituent structure in an utterance-We first address the topic of constituent structure. When signing a transitive sentence about a mouse eating cheese, homesigners in the United States, China, and Turkey are more likely to produce a sign for the patient (e.g., cheese eat) than to produce a sign for the actor (e.g., mouse eat). Actors are produced as often as patients, but only when they are in intransitive sentences (e.g., mouse run). In addition, signs both for intransitive actors and for patients are ordered before the verb in each homesigner's system (Feldman et al. 1978, Goldin-Meadow \& Mylander 1998, Goldin-Meadow 2003c, Goldin-Meadow et al. 2015b). Spoken languages that use this pattern, in which the sole argument in an intransitive sentence shares formal properties with the patient in a transitive sentence rather than with the agent (which is formally distinguished from both), are known as ergative-absolutive languages. Many Caucasian and Mayan languages, among others, are of this type (Anderson 1976, Du Bois 1987, Dixon 1994, and much additional literature). Most of the familiar languages of Europe (with the exception of Basque), such as those of the Romance, Germanic, and Slavic families, as well as Finnish, Turkish, Arabic, and many others, align the sole argument of an intransitive sentence with the agent of a transitive sentence, assigning a distinct form (the accusative) to the patient in the latter case.

Homesigners in the United States and Turkey, in using a pattern that treats intransitive agents and transitive patients alike, thus use a pattern that is characteristic of languages completely different from those of the spoken languages in the surrounding communities. Note that the homesigners' patterns are probabilistic rather than obligatory, but the patterns do provide information about the actor and patient. If, for example, a homesigner produces the utterance 'boy hit,' our best guess is that the boy is being hit (the patient) rather than doing the hitting 
(the actor) precisely because homesigners tend to produce signs for patients rather than transitive actors. Surprisingly, homesigners in the United States, China, and Turkey all display the same ergative constituent structure in their utterances (Goldin-Meadow \& Mylander 1998, Goldin-Meadow et al. 2015b), despite the fact that each homesigner is developing his or her system alone, without contact with other deaf people, and in a different culture.

As another example of constituent structure, homesigners produce combinations of signs that refer to a single entity and are embedded within a larger sign sentence; these combinations thus function as complex nominal constituents (Hunsicker \& Goldin-Meadow 2012; M. Flaherty, D. Hunsicker \& S. Goldin-Meadow, manuscript in preparation). A complex nominal constituent in homesign can contain an iconic sign for an object produced along with a point to the same object, for example, 'coin'- 'point to coin,' meaning that coin, a determiner phrase containing a noun and a demonstrative. When these constituents are embedded within a larger sign sentence, a hierarchical structure is created: [['coinpoint to coin']_- point to self '], meaning [(give) me [that coin]]. Importantly, complex nominal constituents occupy precisely the same position in a sign sentence as single nouns playing the same semantic role (e.g., the patient role in Figure 2), suggesting that complex nominal constituents can substitute for a single noun (Hunsicker \& Goldin-Meadow 2012, Hunsicker 2012). The construction in Figure 2 is an example of hierarchical structure in homesign (see also Goldin-Meadow 1982), which has been considered an essential property of language since the early days of generative linguistics (Chomsky 1956, 1957).

\subsubsection{Morphology: consistent form-meaning mapping at the single-gesture}

level-The signs of child homesigners are composed of a limited set of handshape forms, each standing for a class of objects, and a limited set of motion forms, each standing for a class of actions. There is evidence from the spontaneous productions of child homesigners (Mylander \& Goldin-Meadow 1991; Goldin-Meadow et al. 1995, 2007) that these handshape and motion components combine freely to create novel signs compositionally, rather than being stored as unanalyzed wholes. The meanings of these signs are predictable from the meanings of their component parts. For example, a handling handshape form, such as an -O- with the fingers touching the thumb (meaning 'grasp an object small in diameter'), combined with a 'revolve' motion form (meaning 'rotate around an axis'), means 'rotate a small object around an axis.' Importantly, in terms of arguing that there really is a system underlying the homesigner's gestures, the vast majority of signs that each homesigning child produces conforms to the morphological description for that child, and this finite set of forms can be used to predict new forms. Thus, homesign systems exhibit simple formmeaning pairings using sublexical pieces-a simple morphology - that are internally consistent within a given system (Goldin-Meadow et al. 1995, 2007). Interestingly, it is much more difficult to impose a coherent morphological description onto the cospeech gestures produced by the homesigning children's hearing parents (Goldin-Meadow et al. 1995, 2007), suggesting that morphological structure is not an inevitable outgrowth of the manual modality but is instead a characteristic that the homesigning child imposes on his or her individual communication system. 
There is also evidence for derivational morphology in homesign (Hunsicker \& GoldinMeadow 2013). An American homesigner used object handshapes highlighting the properties of an object (e.g., an index finger representing a long, thin pen) in his early noun gestures, and used handling handshapes highlighting the way the object is held (e.g., a thumb and finger pinch representing how one might hold a long, thin pen) in his early verb gestures. Later in development, he began using place of articulation (specific locations for verbs and a neutral location for nouns; Goldin-Meadow et al. 1994) and movement (larger movements for verbs and smaller movements for nouns; Abner et al. 2015), rather than handshape, to distinguish nouns from verbs.

\subsection{How Close to a Fully Functioning Language Can Homesign Come?}

A plausible hypothesis a priori is that a fully fledged language, whether spoken or signed, can emerge only with the support of a community that can then transmit the system to the next generation. Examining the steps a manual communication system takes as it moves from its homesign stage toward a fully fledged sign language offers a unique window onto factors that have made human language what it is (Goldin-Meadow 2010). Moreover, the historical record suggests that homesign systems formed part of the early raw materials available for sign language genesis in ASL and Brazilian Sign Language (Fusellier-Souza 2006, Supalla \& Clarke 2015); thus, historical data support the view that homesign systems represent a precursor to sign language structure.

Early research on homesign built arguments for morphology and syntax by looking for structure system-internally, and by comparing the gestures homesigning children produced with gestures produced by their hearing parents. Data came from spontaneous interactions between home-signing children and their hearing parents, and from spontaneous play sessions with hearing experimenters. The children studied were quite young (most of the data were collected when the children were between 2 and 5 years of age), which limited the types of constructions that could be explored. But, importantly, this early research established that a child homesign system is internally consistent in form-form relationships at the word-internal level, across words, and within syntactic constituents at the phrase and sentence levels. Ongoing research on sign languages, notably on ASL, which was taking place during the same time and focused on morphology and syntax, served as a backdrop for the early homesign work. As knowledge of both sign language grammars and homesign systems has expanded, more direct comparisons began to appear between signers and homesigners (e.g., Singleton et al. 1993).

In the next section, we compare homesign not with cospeech gesture but rather with fully established languages in the manual communication modality—namely sign languages. We also examine in detail a unique situation in Nicaragua that has allowed us to follow the emergence of language from its homesign beginnings. It was the research in Nicaragua on adult homesigners that opened up the vistas of comparison for homesign systems with their ambient sign language. 


\section{HOMESIGN COMPARED WITH EMERGING AND ESTABLISHED SIGN LANGUAGES}

New sign languages are emerging in several locations around the globe, and thus provide insight into the steps that may have led to the linguistic patterns found in present-day wellestablished sign languages. The circumstances favorable to sign language genesis are a critical number of primary users who interact with each other in the manual modality, and who can transmit the language to new users. These characteristics converge in two general types of situations.

The first situation is one in which there are existing communities that experience a high incidence of deafness, be it genetic or acquired. The languages that arise in this context are called "village" (Meir et al. 2010b) or "rural" (de Vos \& Pfau 2015) sign languages, and often have a high proportion of hearing users. Examples of this type include Martha's Vineyard Sign Language, used in the United States between 1750 and 1900 (Groce 1985); Kata Kolok, currently in use in Bali (de Vos 2012); and Al-Sayyid Bedouin Sign Language (ABSL), used by a group that was previously nomadic and has settled in Israel (Sandler et al. 2005; Padden et al. 2010; Sandler et al. 2011a,b).

The second situation is one in which the language emerges within a community of primarily deaf individuals who are free to communicate manually at, for example, a school for special education or other gathering places for deaf people. Such languages are often referred to as "community" (Meir et al. 2010b) or "urban" (de Vos \& Pfau 2015) sign languages. Community sign languages include ASL, BSL, Italian Sign Language (LIS), French Sign Language, DGS, Russian Sign Language, Polish Sign Language, and Hong Kong Sign Language, among others. Nicaraguan Sign Language (NSL), to which we now turn, is a developing community sign language that gives us the opportunity to watch language as it grows.

NSL has been studied closely as it has developed from its origins in individual homesign systems into a fully fledged community sign language (Kegl et al. 1999, Senghas \& Coppola 2001, Senghas 2003). It has been examined across cohorts and compared with gesture, homesign, and well-established sign languages across cultures. Analyses of adult homesign systems in Nicaragua have uncovered several additional types of linguistic structures not reported in earlier studies on child homesigners. These analyses were possible because the adults were able to respond to tasks that elicited specific types of structures, and because they produced complex narratives that allowed for a wide range of structures to be sampled.

\subsection{Background on the Situation in Nicaragua}

Prior to 1977, deaf individuals in Nicaragua had few opportunities to interact with one another. Between 1977 and 1983, two educational programs were established that served more than 400 deaf students; although instruction was not in sign, students were able to freely communicate with each other using gestures (Polich 2005). The deaf children and adolescents present in the early stages of the formation of NSL had not previously been exposed to, nor acquired, a spoken, written, or signed language. These individuals were like 
the homesigning children studied by Goldin-Meadow and colleagues, described above. But when brought together for the first time, these homesigners had the opportunity to see others use homesign; in other words, for the first time, they were not only producers but also receivers of homesign. This first cohort of NSL users thus allows us to ask whether having a community—in particular, being both a receiver and a producer of a language-changes the structure of that language. NSL gives us the opportunity to ask an additional question about language emergence. Many deaf individuals in Nicaragua are now exposed early in life to NSL-these signers thus learn their language from others. These subsequent cohorts of NSL thus allow us to ask whether transmitting a language to a new set of users changes the structure of that language. By comparing present-day homesigners in Nicaragua with groups whose circumstances have allowed them to go beyond homesign, we can begin to develop hypotheses about which properties of language are resilient (i.e., appear in all systems) and which are fragile (i.e., appear only in select conditions), and which conditions foster the development of these relatively fragile properties.

For the purposes of scholarship, signers in Nicaragua have been divided into groups at critical moments in the emergence of the language: homesigners who lived in hearing households and had not been exposed to any form of sign language, signers who entered the school in the 1980s (Cohort 1) and thus were present during the initial contact stage, and signers who entered the school in the 1980s and thus were present during the sustained contact stage (Cohort 2) (Table 2). Waves of children entering the school after these two cohorts form the subsequent cohorts of NSL signers. In contrast, groups of the village sign language ABSL are referred to as generations, rather than cohorts, because in village sign languages the language is transmitted through actual biological generations of approximately 20 years each.

\subsection{Levels of Linguistic Structure in Nicaraguan Sign Language and Nicaraguan Homesign}

We can observe changes made to a sign system when it remains the homesigner's sole means of communication into adulthood (Coppola \& Newport 2005, Brentari et al. 2012a). Studying adult homesigners allows us to explore the impact that cognitive and social maturity have on linguistic structure. We can also observe changes made to the system when it becomes a community-wide language as homesigners come together for the first time in Cohort 1. Studying Cohort 1 allows us to explore the impact that a community has on linguistic structure- that is, signers who not only produce signs but also receive them as input from their peers. Studying Cohorts 2, 3, and beyond allows us to explore the impact that passing an emerging language through new learners has on linguistic structure. We describe a number of levels of grammatical and lexical structure in each of these groups in the following sections.

3.2.1. Syntax: the notion of subject-Grammatical subjects as syntactic arguments do not have a simple semantic correlate. The subject of a sentence often corresponds to the role of agent (one who intentionally performs an action), but not always. For example, the subject is an agent in the sentence Mary closed the door, but not in the following sentences: The door closed, where the subject is a theme or patient; The mechanical device closed the door, where it is an instrument; and The wind opened the door, where it is an instigator. A 
study of three adult homesigners in Nicaragua demonstrated that the position of the primary argument of the utterance was clause-initial, regardless of its semantic role. Moreover, to confirm that this element was truly a subject and not a discourse topic, the researchers varied the contexts so that sometimes the argument was new information and sometimes it was old information; the pattern was unchanged (Coppola \& Newport 2005). These findings indicate that the construct "grammatical subject" is available to individuals without a linguistic community or a language model.

Research on ABSL has approached the emergence of a grammatical subject in a different way. Meir et al. $(2007,2013)$ argue that the body has three functions in ABSL: not only as a convenient map for referring to actions performed on different body parts but also, importantly, as both a subject marker in verb agreement and a subject argument in a particular range of verbs. The body is argued to be a subject marker of verb agreement in ABSL utterances such as she gives to him, in which the verb TO-GIVE is signed from the body of the signer as a starting point, even though the signer is not the subject. In addition, the body is argued to be a subject argument participating in the event for iconic verbs articulated on the body, the so-called body-anchored verbs such as EAT, where the hand produces a movement as if bringing food to the mouth. This principle applies to several verb types, such as psych verbs, mental activity verbs, verbs of perception, verbs of saying, verbs of change, and change-of-state verbs, all which have the place of articulation on the body itself.

\subsubsection{Lexical form: elaboration of points to new grammatical functions-}

Pointing is ubiquitous, and a close analysis of pointing gestures demonstrates that humans use points from a very young age and in a wider variety of functions than do apes (Tomasello 2008). Pointing gestures are widespread and have been studied extensively in adult hearing speakers (Cooperrider 2014), in the early development of a spoken language (Volterra 1983, 1987; Goldin-Meadow \& Morford 1985; Volterra \& Iverson 1995; Capirci et al. 1996; Cartmill et al. 2014; Goldin-Meadow 2014), in sign languages (Petitto 1987, Fenlon et al. 2013), and in homesign systems (Butcher et al. 1991) and emerging languages, as we discuss in this section. Homesigners, without the benefit of a language model or a community, effortlessly use points for all language functions. Coppola \& Senghas (2010) asked whether these functions have systematically different forms and, if so, whether the differences can already be found in homesign, or whether they require a community of users or a language model to emerge.

Coppola \& Senghas (2010) studied pointing gestures in four groups: adult homesigners in Nicaragua, NSL Cohort 1 signers, NSL Cohort 2 signers, and NSL Cohort 3 signers. All participants saw the same cartoon and were asked to retell the cartoon to a communication partner (i.e., for signers, another member of their cohort; for homesigners, a hearing individual with whom the homesigner communicates regularly). Coppola \& Senghas (2010) analyzed all of the points at empty spaces produced by the groups used for deixis, and classified them according to whether they referred to a location (locative points; he climbed up to the house, while pointing upward) or to a character (nominal points; he was frightened, while pointing to a location in neutral space). They found that the two types of points differed in form. Nominal points were articulated quickly, in the area directly in front of a 
signer's torso, with little or no path movement; in addition, signers rarely followed the direction of a nominal point with their gaze. In contrast, locative points were articulated more slowly and followed longer paths; moreover, signers often followed the direction of a locative point with their gaze (Figure 3 a).

All four Nicaraguan groups produced locative points and did so at about the same rate (Figure $3 b$ ), but nominal points differed as a function of group (Figure $3 b$ ). Nominal points were rarely used by homesigners or Cohort 1 NSL signers; they began to appear with some frequency in Cohort 2, and steadily increased in Cohort 3. These data illustrate how a simple form, such as a point, can be appropriated into a grammatical system, and how form-form relations can become increasingly differentiated as a language develops. Importantly, there was no difference between homesigners and Cohort 1 signers in their use of nominal points —both groups used them infrequently, suggesting that being a producer and a receiver of a language system is not sufficient for this particular form to emerge. The form became a frequent part of the language only when the language was transmitted to the next generation in Cohorts 2 and 3-that is, only when it was learned from a language model.

3.2.3. Discourse: using spatial modulation to indicate arguments-Many wellestablished sign languages use loci in space, and movement toward and away from these loci, to indicate shared reference or coreference (Padden 1988, Meir 2002, Liddell 2003, Abner 2012, Flaherty 2014, Schlenker 2015; J. Fenlon, A. Schembri \& K. Cormier, manuscript under review). These spatial modulations, as they are known, are used to situate arguments in signing space; the marked spaces can then be indicated later to refer back to the arguments. For example, a signer might sign PAY toward her right side, and then subsequently sign GIVE toward the same location, indicating that the same person was both paid and given to. Senghas \& Coppola (2001) found that signers in NSL Cohort 1 and Cohort 2 differed in how they used space to express coreference. Controlling for the number of years of sign language exposure, these authors found that early-exposed Cohort 2 signers (who were exposed to the sign language before the age of 10 years) produced significantly more spatial modulations than did early-exposed Cohort 1 signers. Moreover, Cohort 2 signers were also more likely than Cohort 1 signers to reuse their spatial modulations to track reference across utterances-in other words, to organize their discourse. Spatial modulations thus become a differentiated and multipurpose set of structures in later NSL cohorts, only after the language has been transmitted to, and learned by, a new set of learners.

3.2.4. Morphosyntax: using handshape to express agentivity-A distinction central to all natural languages is agency. For example, the sentence Mary closed the door contains an agent (Mary), but the sentence The door closed does not. Several established sign languages vary handshape type in the verb to capture this opposition (Schick 1987; Zwitserlood 2003, 2012; Benedicto \& Brentari 2004; Mazzoni 2009). In complex verbs known as classifier predicates, handshapes representing properties of the object (object handshapes) are used in the predicate in sentences with a nonagentive subject (e.g., The door closed, in which closed is produced with a handshape showing the flat surface of the door, P), whereas handshapes representing how objects are handled (handling handshapes) are 
used in the predicate in sentences with an agentive subject (e.g., Mary closed the door, in which closed is produced with a handshape showing how one closes a door with a closed fist, 9 ). In a study targeting predicates of this type, Goldin-Meadow et al. (2015a) showed four groups of signers events that varied in whether an agent was present (e.g., a person taking a pen off a table) or not (e.g., a pen sitting on a table): (a) adult Nicaraguan homesigners, (b) NSL Cohort 1 signers, (c) NSL Cohort 2 signers, and (d) native signers of ASL. They found that all four groups used more object handshapes when describing noagent events, and more handling handshapes when describing agent events. Handshape type in the predicate thus varies as a function of grammatical context, and the variation is systematic. In other words, there is morphosyntactic variation as a function of agency, even in adult homesigners, suggesting that neither transmission to a new generation nor having a linguistic community is essential for this grammatical property to emerge in a developing language.

\subsubsection{Word classes: using handshape to distinguish nominals from} predicates-Goldin-Meadow et al. (2015a) analyzed another important property of a grammar-the ability to differentiate lexical categories, in this case nominals versus predicates. They examined consistency in the particular handshape used by each of the four groups in nominal versus predicate signs. They found that all four groups, including homesigners, tended to produce precisely the same handshape for a nominal when it was used in an agent context and in a no-agent context, but varied the handshape for a predicate when it was used in an agent context and in a no-agent context. Figure $4 a$ illustrates this pattern in an ASL signer, who used the same handshape in the nominal signs she produced when labeling the pen in an agent ( $\$$ ) and a no-agent ( $\$$ ) context, but used different handshapes in the predicate signs she produced when describing what happened to the pen

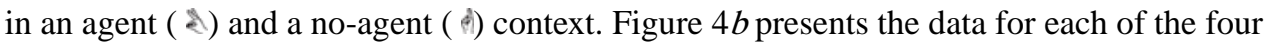
groups. All four groups showed more consistency in the handshapes they used across agent and no-agent contexts in nominals than in predicates, highlighting the fact that nominals and predicates are different types of word classes, even in homesigners.

Goldin-Meadow et al. (2015a) also examined how stable each of the four groups' nominal handshape choices were (e.g., Did the members of a group use the same handshape when describing a variety of pens?). They looked first at stability across individuals within a group and found, not surprisingly, that many of the handshapes used in the ASL group were used by all members of the group. This within-group stability was also found for NSL Cohorts 1 and 2, but not for homesigners (who, of course, do not communicate with one another and thus do not really form a group). However, homesigners also showed little within-individual stability (e.g., each homesigner used three or more different handshapes for the pens), whereas signers in the other three groups (NSL Cohort 1, NSL Cohort 2, ASL) had greater within-individual consistency (each used only one handshape when describing a variety of pens). Stability in nominal forms thus appears to be a linguistic property that individuals will not develop unless they have pressure from a peer linguistic community.

3.2.6. Phonology-Showing that a language has minimal pairs (i.e., words that vary in only one phonological feature, e.g., pat versus bat, which differ only in voicing on the first 
consonant) is often taken as the gold standard for deciding whether the language has phonology. However, minimal pairs, although present, are not common in even established sign languages, such as ASL and BSL, both of which have relatively long histories. But well-established sign languages have other phonological patterns (Brentari 1998, Sandler \& Lillo-Martin 2006) that can be investigated in homesign and emerging sign languages (Brentari \& Eccarius 2010). Handshapes can be grouped into low-, medium-, and highcomplexity forms on the basis of selected finger group complexity (which fingers are moved and contact the body) and joint complexity (whether the knuckles and/or finger joints are flexed). Brentari \& Eccarius (2010) examined patterns of complexity in object and handling handshapes, which are morphological categories, to determine whether these categories also exhibit phonological differences. For example, the handshapes displayed in Figure $5 \mathrm{a}$ form a hypothetical morphological class (a classifier representing whole objects), but the handshapes do not form a phonological class because they share no phonological handshape features-the handshapes contain different fingers, and the fingers are bent, curved, open, and closed. In contrast, each of the two handshape groups displayed in Figure $5 b$ forms both a morphological and a phonological class. Morphological class 1 contains object classifiers (including so-called semantic classifiers), which are typically used to describe situations with no agent; it also contains handshapes high in selected finger group complexity and low in joint complexity. Morphological class 2 contains handling handshapes, which are typically used to describe situations with an agent; it also contains handshapes with the opposite pattern-low in selected finger group and high in joint complexity.

The patterns displayed in Figure $5 b$ are precisely the patterns that Brentari \& Eccarius (2010) found in three unrelated sign languages. Brentari et al. (2012a) asked whether the selected finger group pattern could also be found in four adult homesigners in Nicaragua. They found that three of the four homesigners displayed high complexity in selected finger groups in their object handshapes, and low complexity in selected fingers in their handling handshapes, as did ASL signers and signers of LIS. Interestingly, hearing speakers in the United States and Italy who were communicating with silent gesture (i.e., they were asked to gesture without talking) did not display this pattern, suggesting that the pattern is not inevitable in the manual modality but rather grows out of linguistic structure, not the hand. In addition, Brentari et al. (2016) demonstrated that, across four sign languages, including NSL Cohort 2, the principle of symmetry is at work in the distribution of complexity for both finger and joint features. Both gesturers and signers produce complex handshapes when both joint and finger features are taken into consideration, but only signers balance this complexity across the types of handshapes in a symmetrical way-joint complexity is higher in handling handshapes, whereas finger complexity is higher in object handshapes for signers. Gesturers produce all of their complexity for joints and fingers in handling handshapes, which means that signers actually have less joint complexity in handling handshapes than gesturers do. The finding of a symmetrical distribution of handshape features in sign language (but not silent gesture) is in agreement with results from Lindblom et al. (1984) and Lindblom (1992), who observed that phonological systems tend to be symmetrical. In addition, using a computational model to predict the shape of phonological inventory, Wedel (2004) found that phonological contrast systems tend to make use of symmetrical inventories, rather than widely scattered contrasts. Like many of the patterns 
described above, this pattern has predictive power. These form-form pairings, based on a simple phonology that is internally consistent, provide the user with a systematic way to add new forms. New forms that are created should conform to this pattern.

In other research on the emergence of phonology in sign languages, Sandler et al. (2011a) argued that because ABSL has neither minimal pairs nor the type of feature spreading rules (assimilation) commonly found crosslinguistically, it does not yet have phonology. They state that "ABSL might therefore get along very well without dual patterning [phonology], and, as we argue, it does" (Sandler et al. 2011a, p. 507). We agree that, ultimately, phonology must demonstrate systematic behavior, preferably of several kinds-including minimal pairs and phonological rules that are shared across a language community-but argue that the patterns that appear early in emergence in NSL constitute the first steps toward this more mature phonological state.

We interpret the emergence of systematic patterns in handshape complexity in NSL as one of the first indications of phonological organization (Brentari et al. 2012a, 2016) even though the system does not exhibit duality of patterning (Hockett 1960); the morphological and phonological groupings simply align with one another. These findings accord well with Ladd's (2014) recent argument that duality of patterning need not be an acid test for a phonological system. Handling and object handshape classes exhibit coextensive organization at the phonological and morphological levels, displaying systematicity in both components of the grammar and thus providing evidence for structure at both levels. This example helps clarify the way that iconicity and arbitrariness are intertwined in sign languages, in general, and in sign language phonology, in particular. Iconicity is present in handling and object handshapes in sign language, but it is reorganized and restructured in the ways just described to assume a pattern than can be best described as phonological.

3.2.7. Prosody: the "medium" of language-Prosody is the way language is delivered -its phrasing (where the boundaries are), prominence (emphasis on what is important), and rhythm. Prosody also has important interactions with syntax. For example, clauses are typically followed by a pause; the English phrase milk, bottles, and chocolate, with a pause after milk and bottles, is broken up differently in syntax than the phrase milk bottles, and chocolate, with a pause only after bottles. There are also prosodic dependencies between clauses, as in an If $x$, then $y$ sentence (e.g., If it rains, we won't play tennis). In addition, rhythm is important for understanding whether a string is a compound or not; for example, white 'house (with stress on house) is a phrase, whereas 'white house (with stress on white) is a compound word.

Established sign languages use affective and specific nonmanual (primarily facial) behaviors, which can also serve grammatical functions, for prosodic marking (Nespor \& Sandler 1999, Sandler 2012). The timing of facial cues, and the extent to which they spread, marks constituents in sign languages, particularly the intonational phrase, which is often associated with the syntactic domain of the clause (although it is not isomorphic with it). Although prosody has not yet been examined in emerging languages in Nicaragua, Sandler et al. (2011b) have explored this feature in ABSL signers. They found that both older and younger ABSL signers use abundant facial expressions, but the two groups use them 
differently. Younger signers produce facial expressions that are grammatical (rather than affective) more frequently than older signers - they time their facial expressions with intonational phrase boundaries, and they use prosodic cues to create dependencies between clauses (e.g., If $x$, then $y$ ). Older ABSL signers from previous generations use prosodic cues, but they do not time them well with constituent boundaries, nor do they use them to signal clausal dependencies. As in the pointing example discussed above, a simple behavior like affective facial expressions can be appropriated by the later generations of an emerging system to be used for complex linguistic purposes.

Applebaum et al. (2014) examined prosody in an American homesigning child and found that the child used features known to mark phrase and utterance boundaries in established sign languages to consistently mark the ends of his gesture sentences (phrasing), although he did not use these features to mark phrase- or sentence-internal boundaries. The first use of prosody can thus be found in a homesigning child. In the future, it will be important to compare the homesigner's use of prosody with the same features in hearing children's gestures (e.g., Balog \& Brentari 2008) and in deaf children's signs (e.g., Brentari et al. $2015 b$ ) to determine whether limitations in the homesigner's prosodic structure stem from the fact that he is creating the system, or from the fact that he is a child.

\section{SURPRISING RESULTS AND FURTHER IMPLICATIONS OF WORK ON LANGUAGE EMERGENCE}

\subsection{Language Emergence and Language Acquisition}

Having mounted evidence for two crucial points about emerging language- that homesign systems are not simple elaborations of ambient cospeech gesture, and that some properties of language can emerge without a linguistic community or a language model—we are now in a position to ask whether homesigners look like children learning language from a model but on a longer time course. The discussion presented above suggests that the answer is "sometimes, but not always"- that even though language emergence and language acquisition are obviously related, they are different in important ways. Children bring the same set of skills to language acquisition and to language emergence, but how they deploy those skills is likely to depend on the nature of the input they receive-a linguistic model in the case of acquisition, cospeech gesture in the homesign cases of language emergence described here. Two ways in which the process of language emergence and language acquisition differ are discussed below.

4.1.1. Grammar before a stable vocabulary-Goldin-Meadow et al. (2015a) have shown that a stable vocabulary is not likely without a linguistic community. The homesigners in their study displayed very little stability in the handshapes they used in their nominal labels for an object. Importantly, however, the homesigners did use handshape consistently as a morphological marker on their predicates. Thus, unlike the lexical use of handshape, which does not appear to stabilize unless there is pressure from a peer linguistic community (Richie et al. 2014), the grammatical use of handshape (e.g., morphosyntactic contrast in agency) can be found in the earliest stages of an emerging language. In contrast, children acquiring language from a model learn word forms before they learn grammatical 
markers (Locke 1993, Clark 2009). The fact that some grammatical properties emerge before a stable vocabulary during language emergence but not during language acquisition might be considered surprising — but not when we consider the fact that one of the main purposes of a vocabulary is to share it, and to talk about events and objects in the world in a common way with members of a linguistic community. Establishing a stable vocabulary is a type of negotiation among community members collectively deciding which forms to incorporate, keep, or discard. The intriguing point is that having a stable vocabulary does not appear to be a necessary prerequisite for the emergence of at least some grammatical properties.

4.1.2. Interface phenomena before "pure" phonology-In the phonological development of children acquiring a first language, phonotactic patterns such as syllable structure appear even before the forms are associated with any meaning (see DePaolis et al. 2008 for spoken language; see Petitto \& Marentette 1991 and Petitto et al. 2004 for sign language). Moreover, by the time children exhibit a vocabulary of approximately 50 words, there is evidence of distinctive features that create minimal pairs, such as pat, bat (Locke 1993), which has been attributed to the need to catalogue the growing lexicon. This early linguistic activity of "form for form's sake" is different from the phonological handshape patterns discussed above, where the phonological representations of object and handling handshapes were aligned with meaningful morphological representations in both homesigning adults and users of established sign languages. In this case, one might say that the phonology is baked into the morphology - that is, at the interface between phonology and morphology.

Despite the phonological-morphological alignment, the two levels of representation do not appear at the same time in development, either in acquisition or in emergence (Brentari et al. 2013, 2015a, 2016; Coppola \& Brentari 2014). Children acquiring ASL or LIS as a first language show the phonological pattern of handshape complexity depicted in Figure 5 for object and handling handshapes by age 4 (Brentari et al 2015a, 2016), but the morphological agentive/nonagentive distinction is not mastered until age 7-8 in ASL (Schick 1987, Brentari et al. 2013). The results from a longitudinal study of one child homesigner in Nicaragua show the same pattern (i.e., phonology before morphology): Handshape complexity (a phonological pattern) emerged over a 5-year span (age 7-12), but at age 12 the agentive/nonagentive opposition (a morphological pattern) had not yet appeared (Coppola \& Brentari 2014). The independence of phonological and morphological representations over the course of development is evidence for the independence of these levels of representation, even if the two are aligned. Accordingly, our findings align more closely with those found for typical language acquisition in spoken and sign languages (MacWhinney 1978, Ravid \& Schiff 2009), namely that phonology precedes morphology. The research on ABSL argues for a different conclusion with regard to which component appears first—phonology or morphology. Sandler et al. (2011a) have argued that, because ABSL lacks duality of patterning but uses spatial devices for morphological verb agreement (Sandler et al. 2005, Meir et al. 2013), morphology precedes phonology in ABSL.

We suggest three possible explanations for the different conclusions based on NSL versus ABSL data. First, the conclusions for NSL (phonology precedes morphology) are based on 
two handshape phenomena that are closely related-the same handshapes are involved in the handshape complexity phenomena (phonology) and agentive/nonagentive opposition (morphology). In contrast, the conclusions for ABSL (morphology precedes phonology) are based on two very different phenomena - the lack of duality of patterning in frozen lexical items (phonology) and verb agreement (morphology). We suggest that related phenomena are a better test case for deciding componential order of emergence, as different grammatical phenomena may proceed along different time courses of language emergence or acquisition. Second, the analyses of NSL and ABSL have placed the threshold for calling a phenomenon "phonology" in a different place. The symmetrical distribution of finger and joint features of handshapes drawn from NSL is a less stringent criterion for a phonological system than the minimal pair criterion used for ABSL. This debate goes to the very heart of what constitutes phonological structure. A third reason for the differences in conclusions is discussed further below; specifically, NSL is a community sign language, whereas ABSL is a village sign language, and this difference may matter for language emergence.

\subsection{Not All Emerging Languages Are Alike}

An open question is whether there are important differences between sign languages that emerge in a village or rural setting and sign languages that emerge in a community or urban setting. Differences between these two types of emerging languages have, in fact, been found in kinship terms and pointing gestures (de Vos \& Pfau 2015).

With respect to kinship terms, community sign languages have been found to have a wide range of terms and systems for expressing kinship [e.g., Asian sign languages (Fischer \& Dong 2010), NSL (M. Coppola \& A. Senghas, personal communication)]. In contrast, the only village sign language whose kinship system has been studied, Kata Kolok, a village sign language of Bali, is reported to have only three kinship terms-mother, father, offspring —placing it among the most restricted kinship systems in the world.

With regard to pointing signs, we have seen that in NSL, a community sign language, deictic points become differentiated and express both locative and nominal meanings in Cohort 2. In contrast, in Kata Kolok, a village sign language, pointing signs are not produced in arbitrary loci in space at all (i.e., there are no points at empty spaces). Pointing signs exist, of course, and they are frequently used, but they target only absolute loci, such as the location of a present referent or the direction in which a house can be found (in order to refer to a person living in that house). In other words, the "direction of a pointing sign is motivated by shared background knowledge of individuals and associated geographic locations" (de Vos 2012, p. 197).

Meir et al. (2010b) have proposed that village sign languages develop on a slower time course than community sign languages because they have a smaller proportion of deaf users relative to hearing users, who do not use the system as their primary means of communication. In a community sign language, most of the users are deaf and so use the system as their primary communication system. Using a system as a primary language facilitates economy and efficiency, and may encourage rapid innovation. This factor may explain some of the different conclusions about language emergence that have come out of studies of NSL versus ABSL. In addition, village sign languages often disappear if the 
environmental factors related to the genetic transmission of deafness disappear, as they did on Martha's Vineyard (Groce 1985). As the gene pool diversified when travel between the mainland and Martha's Vineyard became more efficient, less expensive, and less time consuming, Martha's Vineyard Sign Language disappeared. Community sign languages are more robust because they do not depend on transmission within families.

\subsection{Effects on Sign Language Research}

Studying the trajectory of language emergence has had an interesting effect on the study of sign languages. Because so much attention needs to be paid to the stability of an emerging system, researchers working on well-established sign languages have come to recognize the importance of also documenting stability in established sign languages. Of course, sociolinguists have always been interested in questions of this sort. But it is now common methodological practice that, each time a task is used to examine an emerging language, comparable data are collected on at least one well-established sign language to determine the range of variation in a language that is not undergoing dramatic change. Only by establishing a genuine baseline of variation for well-established sign languages can we determine whether a structure is or is not relatively stable in an emerging language.

\subsection{Effects on Gesture Research}

A new set of questions has arisen in the study of gesture, both cospeech gesture and silent gesture. For example, researchers are exploring whether speakers use gesture in spoken language prosody, called audio-visual prosody (Krahmer \& Swerts 2005, 2007); these patterns can then be compared with the patterns found in sign language prosody to explore similarities and differences. As another example, researchers are exploring the ability of nonsigners (who have only their skills as gesturers to draw on) to understand patterns in sign language — sign language prosody (Fenlon et al. 2007, Brentari et al. 2011) and sign language structures that encode notions of telicity (Strickland et al. 2015). Researchers are also exploring whether hearing people who have experience using cospeech gesture will have a different "accent" when they sign, not because they learned to sign as a second language but simply because they have had extensive cospeech gesture experience. For example, there appear to be differences between the signing of deaf children of deaf parents and hearing children of deaf parents, both of whom learn ASL as a first language (Brentari et al. 2012b). Finally, researchers have asked whether signers gesture (Duncan 2005) and, if so, whether cosign gesture serves the same cognitive functions as cospeech gesture (GoldinMeadow et al. 2012). The large number of potential areas of crossover abilities between cospeech gesture and sign offers opportunities to explore the set of manual abilities that are ultimately exploited for grammatical purposes in emerging and established sign languages (see Goldin-Meadow \& Brentari 2016 for further discussion).

There is also burgeoning research on silent gesture. As mentioned above, when hearing speakers are asked to turn off their voices and use only their hands to communicate, these silent gestures take on linguistic properties not seen in cospeech gesture (Goldin-Meadow et al. 1996), perhaps because gesture without voice must bear the whole communicative burden (Singleton et al. 1993, Schembri et al. 2005). To the extent that a silent gesturer who knows no sign language can invent structures found in established sign language, we have evidence 
for the "naturalness" of those structures. For example, there is evidence for the systematic use of location to establish coreference in silent gesture (So et al. 2005), as well as consistent ordering in how gestures are combined into strings in silent gesture (GershkoffStowe \& Goldin-Meadow 2002). Interestingly, the order found in silent gesture is the same, regardless of the gesturer's spoken language (Goldin-Meadow et al. 2008, Langus \& Nespor 2010, Meir et al. 2010a, Gibson et al. 2013, Hall et al. 2013). In other words, the order in silent gesture does not necessarily mirror the order found in the gesturer's spoken language, suggesting that it is an invented structure that can provide insight into universally accessible linguistic biases (Özçalı̧̧kan et al. 2016).

Both cospeech gesture and silent gesture can contribute to our understanding of the raw materials out of which newly emerging linguistic systems have arisen. It may be that the properties of homesign are waiting to appear in all of us - they simply may not have a chance to emerge because we use a learned system (either spoken or signed) as our primary means of communication.

\section{CONCLUSION}

There are many questions about language emergence still left to answer. An obvious one is whether our descriptions of language emergence are limited because the only places we find it are in the visual modality. In other words, would the steps that an emerging spoken language follows look the same as the steps that we have described for emerging sign languages? In the end, this may be an unanswerable question, given how difficult it is to explore language emergence in the oral modality.

Other important questions concern the nature of the individuals with whom the creator of the language communicates. It is clearly advantageous to be in a language community, but is there an advantage for a homesigner to having another homesigner in her home or in school? Does it matter if the two homesigners are peers of roughly the same age, or is it better to have one homesigner be older so that the younger one can build on what she sees? Does a homesigner's language skill peak at some point (perhaps at the end of the critical period for language development), or does homesign continue to develop throughout the life span (perhaps as a function of the type of experience the individual has at work or at home)?

The manual modality can take on linguistic properties, even in the hands of a young child not yet exposed to a conventional language model. But it grows into a full-blown language only with the support of a community that can transmit the system to the next generation. Examining the steps a manual communication system takes as it moves toward becoming a fully fledged sign language offers a unique window onto factors that have made human language what it is.

\section{Supplementary Material}

Refer to Web version on PubMed Central for supplementary material. 


\section{Glossary}

\section{Homesign systems}

self-created systems of communication used by deaf individuals who have not been exposed to a sign language, and who do not read or write the ambient spoken language

\section{Gesture}

movement of the head, hands, and body produced by hearing individuals while they are speaking (cospeech gesture) or when they are asked to communicate without talking (silent gesture)

\section{Sign languages}

visual-gestural languages that have arisen within deaf communities around the world; they have the same levels of lexical and grammatical structure as spoken languages

\section{Syntactic argument}

an expression that is obligatory to complete the meaning of a predicate; for example, the English verb drop requires two arguments, typically the person who dropped the object and the thing that was dropped

\section{Ergative-absolutive pattern}

a relationship between form and meaning at the sentence level, whereby the actor in an intransitive sentence is structurally aligned with the patient, and not with the actor

\section{Deixis}

refers to words whose meaning "shift" in the discourse, indicating entities from a particular point of view with respect to the time of the speech act

\section{Coreference}

systems for tracking reference in a discourse, often allowing reduced forms to refer back to the same noun

\section{Spatial modulation}

the use of space in a sign language to track reference, as seen in, for example, pronouns, possessive markers, verbal agreement markers, and locative terms

\section{Agency}

a scale along which syntactic arguments can be rated according to how capable they are of carrying out volitional acts, for instance, human $>$ animal $>$ natural force $>$ abstraction

\section{Selected finger group}

the phonological property of handshape that determines which fingers are used in the handshape; handshapes using all the fingers, or only the index finger, are the least complex specifications

\section{Joint}


the phonological property of handshape that determines which joints of the fingers are flexed in the handshape: metacarparal (knuckes) or interphalangeal; handshapes using all or no joints (totally open or closed) are the least complex

\section{Duality of patterning}

the property of language that refers to the fact that phonology and morphology are organized independently (Hockett 1960), for example, syllables (phonological) versus morphemes (morphological)

\section{LITERATURE CITED}

Abner, N. PhD thesis. Dep. Linguist., Univ. Calif; Los Angeles: 2012. There once was a verb: the predicative core of possessive and nominalization structures in American Sign Language; p. 175

Abner, N., Flaherty, M., Stangl, K., Brentari, D., Goldin-Meadow, S. Emergent lexical categories: nouns and verbs in homesign and Nicaraguan Sign Language. Presented at Formal and Experimental Approaches to Sign Language Theory (FEAST); Barcelona, Spain. May 4-6; 2015.

Anderson, SR. On the notion of subject in ergative languages. In: Li, C., editor. Subject and Topic. New York: Academic; 1976. p. 1-24.

Anderson, SR. Doctor Dolittle's Delusion: Animals and the Uniqueness of Human Language. New Haven: Yale Univ. Press; 2004.

Applebaum L, Coppola M, Goldin-Meadow S. Prosody in a communication system developed without a language model. Sign Lang Linguist. 2014; 17:181-212. [PubMed: 25574153]

Balog H, Brentari D. The relationship between early gestures and intonation. First Lang. 2008; 28:141-63.

Battison, R. Lexical Borrowing in American Sign Language. Silver Spring, MD: Linstok; 1978.

Benedicto E, Brentari D. Where did all the arguments go? Argument-changing properties of classifiers in ASL. Nat Lang Linguist Theory. 2004; 22:1-68.

Brentari, D. A Prosodic Model of Sign Language Phonology. Cambridge, MA: MIT Press; 1998.

Brentari, D. Sign Languages: A Cambridge Language Survey. Cambridge, UK: Cambridge Univ. Press; 2010.

Brentari D, Coppola M, Mazzoni L, Goldin-Meadow S. When does a system become phonological? Handshape production in gesturers, signers, and homesigners. Nat Lang Linguist Theory. 2012a; 30:1-31. [PubMed: 23723534]

Brentari D, Di Renzo A, Keane J, Volterra V. Cognitive, cultural, and linguistic sources of a handshape distinction expressing agentivity. TopiCS. 2015a; 7:95-123. [PubMed: 25529989]

Brentari D, Coppola M, Cho PW, Senghas A. Handshape complexity as a precursor to phonology: variation, emergence, and acquisition. Lang Acquis. 2016 In press.

Brentari D, Coppola M. What sign language creation teaches us about language. Wiley Interdiscip Rev Cogn Sci. 2013; 4:201-11. [PubMed: 26304196]

Brentari D, Coppola M, Jung A, Goldin-Meadow S. Acquiring word class distinctions in American Sign Language: evidence from handshape. Lang Learn Dev. 2013; 9:130-50. [PubMed: 23671406]

Brentari, D., Eccarius, P. Handshape contrast in sign languages. In: Brentari, D., editor. Sign Languages. Cambridge, UK: Cambridge Univ. Press; 2010. p. 284-311.

Brentari D, Falk J, Wolford G. The acquisition of American Sign Language prosody. Phonol Anal. 2015b; 91:144-68.

Brentari D, González C, Seidl A, Wilbur R. Sensitivity to visual prosodic cues in signers and nonsigners. Lang Speech. 2011; 54:49-72. [PubMed: 21524012]

Brentari D, Nadolske M, Wolford G. Can experience with gesture influence the prosody of a sign language? ASL prosodic cues in bimodal bilinguals. Biling Lang Cogn. 2012b; 15:402-12.

Butcher C, Mylander C, Goldin-Meadow S. Displaced communication in a self-styled gesture system: pointing at the non-present. Cogn Dev. 1991; 6:315-42. 
Capirci O, Iverson JM, Pizzuto E, Volterra V. Communicative gestures during the transition to twoword speech. J Child Lang. 1996; 23:645-673.

Cartmill E, Hunsicker D, Goldin-Meadow S. Pointing and naming are not redundant: Children use gesture to modify nouns before they modify nouns in speech. Dev Psychol. 2014; 50:1660-66. [PubMed: 24588517]

Chomsky N. Three models for the description of language. IRE Trans Inf Theory. 1956; 2:113-24.

Chomsky, N. Syntactic Structures. The Hague/Paris; Mouton: 1957.

Clark, EV. First Language Acquisition. Cambridge, UK: Cambridge Univ. Press; 2009.

Cooperrider K. Body-directed gestures: pointing to the self and beyond. J Pragmat. 2014; 71:1-16.

Coppola M, Brentari D. From iconic handshapes to grammatical contrasts: longitudinal evidence from a child homesigner. Front Psychol Lang Sci. 2014; 5:830.

Coppola M, Newport E. Grammatical subjects in homesign: abstract linguistic structure in adult primary gesture systems without linguistic input. PNAS. 2005; 102:19249-53. [PubMed: 16357199]

Coppola, M., Senghas, A. Deixis in an emerging sign language. In: Brentari, D., editor. Sign Languages: A Cambridge Language Survey. Cambridge, UK: Cambridge Univ. Press; 2010. p. 543-69.

Davis, J. A historical linguistic account of sign language among North American Indian groups. In: Lucas, C., editor. Multilingualism and Sign Languages: From the Great Plains to Australia; Sociolinguistics of the Deaf Community. Vol. 12. Washington, DC: Gallaudet Univ. Press; 2006. p. 3-35.

de Vos, C. PhD thesis. Radboud Univ; Nijmegen, Neth: 2012. Sign-spatiality in Kata Kolok: how a village sign language of Bali inscribes its signing space.

de Vos C, Pfau R. Sign language typology: the contribution of rural sign languages. Annu Rev Linguist. 2015; 1:265-88.

DeGraff, M. Language Creation and Language Change: Creolization, Diachrony and Development. Cambridge, MA: MIT Press; 1999.

DeGraff M. On the origin of Creoles: a Cartesian critique of Neo-Darwinian linguistics. Linguist Typol. 2001; 5.2/5.3:213-310.

DePaolis R, Vihman M, Kunnari S. Prosody in production at the onset of word use: a cross-linguistic study. J Phon. 2008; 36:406-22.

Dixon, RMW. Ergativity. Cambridge, UK: Cambridge Univ. Press; 1994.

Duncan S. Gesture in signing: a case study from Taiwan Sign Language. Lang Linguist. 2005; 6:279_ 318.

Du Bois J. The discourse basis of ergativity. Language. 1987; 63:805-55.

Feldman, H., Goldin-Meadow, S., Gleitman, L. Beyond Herodotus: the creation of language by linguistically deprived deaf children. In: Lock, A., editor. Action, Symbol, and Gesture: The Emergence of Language. New York: Academic; 1978. p. 351-414.

Fenlon J, Denmark T, Campbell R, Woll B. Seeing sentence boundaries. Sign Lang Linguist. 2007; 10:177-200.

Fenlon J, Schembri A, Rentelis R, Cormier K. Variation in handshape and orientation in British Sign Language: the case of the ' 1 ' hand configuration. Lang Commun. 2013; 33:69-91. [PubMed: 23805018]

Fischer, S., Dong, Q. Variation in East Asian sign language structures. In: Brentari, D., editor. Sign Languages: A Cambridge Language Survey. Cambridge: Cambridge Univ. Press; 2010. p. 502-21.

Flaherty, M. PhD thesis. Dep. Psychol., Univ; Chicago: 2014. The emergence of argument structural devices in Nicaraguan Sign Language; p. 125

Frishberg N. Arbitrariness and iconicity. Language. 1975; 51:696-719.

Fusellier-Souza I. Emergence and development of signed languages: from a semiogenetic point of view. Sign Lang Stud. 2006; 7:30-56.

Gershkoff-Stowe L, Goldin-Meadow S. Is there a natural order for expressing semantic relations? Cogn Psychol. 2002; 45:375-412. [PubMed: 12480479] 
Gibson E, Piantadosi ST, Brink K, Bergen L, Lim E, Saxe R. A noisy-channel account of crosslinguistic word order variation. Psychol Sci. 2013; 24:1079-88. [PubMed: 23649563]

Goldin-Meadow, S. The resilience of recursion: a study of a communication system developed without a conventional language model. In: Wanner, E., Gleitman, LR., editors. Language Acquisition: The State of the Art. NewYork: Cambridge Univ. Press; 1982. p. 51-77.

Goldin-Meadow, S. Hearing Gestures: How Our Hands Help Us Think. Cambridge, MA: Harvard Univ. Press; 2003a.

Goldin-Meadow, S. The Resilience of Language: What Gesture Creation in Deaf Children Can Tell Us About How All Children Learn Language. New York: Psychology; 2003b.

Goldin-Meadow, S. Thought before language: Do we think ergative?. In: Gentner, D., Goldin-Meadow, S., editors. Language in Mind: Advances in the Study of Language and Thought. Cambridge, MA: MIT Press; 2003c. p. 493-522.

Goldin-Meadow S. What language creation in the manual modality tells us about the foundations of language. Linguist Rev. 2005; 22:199-225.

Goldin-Meadow S. Widening the lens on language learning: language in deaf children and adults in Nicaragua. Hum Dev. 2010; 53:235-312.

Goldin-Meadow, S. How gesture helps children learn language. In: Arnon, I.Tice, M.Kurumada, C., Estigarribia, B., editors. Language in Interaction: Studies in Honor of Eve V. Clark. Amsterdam: Benjamins; 2014. p. 157-71.

Goldin-Meadow S. The impact of time on predicate forms in the manual modality: signers, homesigners, and silent gesturers. Top Cogn Sci. 2015; 7:169-84. [PubMed: 25329421]

Goldin-Meadow S, Brentari D. Gesture, sign and language: the coming of age of sign language and gesture studies. Brain Behav Sci. 2016; :39. In press. doi: 10.1017/S0140525X15001247

Goldin-Meadow S, Brentari D, Coppola M, Horton L, Senghas A. Watching language grow in the manual modality: nominals, predicates, and handshapes. Cognition. 2015a; 136:381-95. [PubMed: 25546342]

Goldin-Meadow S, Butcher C, Mylander C, Dodge M. Nouns and verbs in a self-styled gesture system: What's in a name? Cogn Psychol. 1994; 27:259-319. [PubMed: 7828423]

Goldin-Meadow S, Feldman H. The development of language-like communication without a language model. Science. 1977; 197:401-3. [PubMed: 877567]

Goldin-Meadow S, McNeill D, Singleton J. Silence is liberating: removing the handcuffs on grammatical expression in the manual modality. Psychol Rev. 1996; 103:34-55. [PubMed: 8650298]

Goldin-Meadow S, Morford M. Gesture in early child language: studies of deaf and hearing children. Merrill-Palmer Q. 1985; 31:145-76.

Goldin-Meadow S, Mylander C. Gestural communication in deaf children: the non-effects of parental input on language development. Science. 1983; 221:372-74. [PubMed: 6867713]

Goldin-Meadow S, Mylander C. Gestural communication in deaf children: the effects and non-effects of parental input on early language development. Monogr Soc Res Child Dev. 1984; 49:1-121.

Goldin-Meadow S, Mylander C. Spontaneous sign systems created by deaf children in two cultures. Nature. 1998; 391:279-81. [PubMed: 9440690]

Goldin-Meadow S, Mylander C, Butcher C. The resilience of combinatorial structure at the word level: morphology in self-styled gesture systems. Cognition. 1995; 56:195-262. [PubMed: 7554795]

Goldin-Meadow S, Mylander C, Franklin A. How children make language out of gesture: morphological structure in gesture systems developed by American and Chinese deaf children. Cogn Psychol. 2007; 55:87-135. [PubMed: 17070512]

Goldin-Meadow S, Namboodiripad S, Mylander C, Ozyurek A, Sancar B. The resilience of structure built around the predicate: homesign gesture systems in Turkish and American deaf children. J Cogn Dev. 2015b; 16:55-88. [PubMed: 25663828]

Goldin-Meadow S, Shield A, Lenzen D, Herzig M, Padden C. The gestures ASL signers use tell us when they are ready to learn math. Cognition. 2012; 123:448-53. [PubMed: 22421166]

Goldin-Meadow S, So W-C, Ozyurek A, Mylander C. The natural order of events: how speakers of different languages represent events nonverbally. PNAS. 2008; 105:9163-68. [PubMed: 18599445] 
Goldin-Meadow S, Yang C. Statistical evidence that a child can create a combinatorial linguistic system without linguistic input: implications for language evolution. Neurosci Biobehav Rev. 2016 In press.

Groce, NE. Everyone Here Spoke Sign Language: Hereditary Deafness on Martha's Vineyard. Cambridge, MA: Harvard Univ. Press; 1985.

Hall ML, Ferreira VS, Mayberry RI. Investigating constituent order change with elicited pantomime: a functional account of SVO emergence. Cogn Sci. 2013; 38:943-72.

Hockett CF. The origin of speech. Sci Am. 1960; 203:88-96. [PubMed: 13683472]

Hunsicker, D. PhD thesis. Dep. Psychol., Univ; Chicago: 2012. Complex nominal constituent development in Nicaraguan homesign; p. 116

Hunsicker D, Goldin-Meadow S. Hierarchical structure in a self-created communication system: building nominal constituents in homesign. Language. 2012; 88:732-63. [PubMed: 23626381]

Hunsicker D, Goldin-Meadow S. How handshape type can distinguish between nouns and verbs in homesign. Gesture. 2013; 13:354-76.

Kegl, J., Senghas, A., Coppola, M. Creation through contact: sign language emergence and sign language change in Nicaragua. In: DeGraff, M., editor. Language Creation and Language Change: Creolization, Diachrony, and Development. Cambridge, MA: MIT Press; 1999. p. 179-237.

Kendon, A. Gesture and speech: two aspects of the process of utterance. In: Key, MR., editor. Nonverbal Communication and Language. The Hague; Mouton: 1980. p. 207-27.

Kendon A, Cook M. Consistency of gaze patterns in social interaction. Br J Psychol. 1969; 60:481-94. [PubMed: 5358951]

Klima, E., Bellugi, U. The Signs of Language. Cambridge, MA: Harvard Univ. Press; 1979.

Krahmer E, Swerts M. How children and adults produce and perceive uncertainty in audiovisual speech. Lang Speech. 2005; 48:29-54. [PubMed: 16161471]

Krahmer E, Swerts M. The effects of visual beats on prosodic prominence: acoustic analyses, auditory perception and visual perception. J Mem Lang. 2007; 57:396-414.

Ladd, R. Simultaneous Structure in Phonology. Oxford, UK/New York: Oxford Univ. Press; 2014.

Langus A, Nespor M. Cognitive systems struggling for word order. Cogn Psychol. 2010; 60:291-318. [PubMed: 20189553]

Liddell, S. Grammar, Gesture, and Meaning in American Sign Language. Cambridge, UK: Cambridge Univ. Press; 2003.

Lightfoot, D. The Development of Language: Acquisition, Change and Evolution. Oxford, UK: Blackwell; 1999.

Lindblom, B. Phonological units as adaptive emergents of lexical development. In: Ferguson, CA.Menn, L., Stoel-Gammon, C., editors. Phonological Development: Models, Research, Implications. Timonium, MD: York; 1992. p. 131-63.

Lindblom, B., MacNeilage, P., Studdert-Kennedy, M. Self-organizing processes and the explanation of language universals. In: Butterworth, B.Comrie, B., Dahl, Ö., editors. Explanations for Language Universals. Berlin: de Gruyter; 1984. p. 181-203.

Locke, J. The Child's Path to Spoken Language. Cambridge, MA: Harvard Univ. Press; 1993.

Lucas, C., Valli, C. Linguistics of American Sign Language: A Resource Text for ASL Users. Washington, DC: Gallaudet Univ. Press; 1992.

MacWhinney, B. Monographs for the Society for Research in Child Development, vol. 43: The Acquisition of Morphophonology. Oxford, UK: Blackwell; 1978.

Mazzoni, L. Classificatori e Impersonamento nella Lingua dei Segni Italiana. Pisa: Plus; 2009.

McNeill, D. Hand and Mind: What Gestures Reveal About Thought. Chicago: Univ. Chicago Press; 1992.

McNeill, D. Language and Gesture. Cambridge, UK/NewYork: Cambridge Univ. Press; 2000.

McNeill, D. Gesture and Thought. Chicago: Univ. Chicago Press; 2005.

Meir I. Across-modality perspective on verb agreement. Nat Lang Linguist Theory. 2002; 20:413-50.

Meir I, Padden CA, Aronoff M, Sandler W. The body as subject. J Linguist. 2007; 43:531-63. [PubMed: 23066169] 
Meir, I., Lifshitz, A., Ilkbasaran, D., Padden, C. The interaction of animacy and word order in human languages: a study of strategies in a novel communication task. In: Smith, ADM.Schouwstra, M.de Boer, B., Smith, K., editors. Proceedings of the 8th Evolution of Language Conference. Singapore: World Sci; 2010a. p. 455-56.

Meir, I., Sandler, W., Padden, C., Aronoff, M. Emerging sign languages. In: Marschark, M., Spencer, P., editors. Oxford Handbook of Deaf Studies, Language, and Education. Vol. 2. Oxford, UK: Oxford Univ. Press; 2010b. p. 267-80.

Meir I, Padden CA, Aronoff M, Sandler W. Competing iconicities in the structure of language. Cogn Linguist. 2013; 24:309-43.

Mylander, C., Goldin-Meadow, S. Home sign systems in deaf children: the development of morphology without a conventional language model. In: Siple, P., Fischer, SD., editors. Theoretical Issues in Sign Language Research, vol. 2: Psychology. Chicago: Univ. Chicago Press; 1991. p. 41-63.

Nespor M, Sandler W. Prosody in Israeli Sign Language. Lang Speech. 1999; 42:143-76.

Newport, EL. Reduced input in the acquisition of signed languages: contributions to the study of creolization. In: DeGraff, M., editor. Language Creation and Language Change: Creolization, Diachrony, and Development. Cambridge, MA: MIT Press; 1999. p. 161-78.

Özçalışkan S, Lucero C, Goldin-Meadow S. Does language shape silent gesture? Cognition. 2016; 148:10-18. [PubMed: 26707427]

Padden, C. Interaction of Morphology and Syntax in American Sign Language. New York: Garland Press; 1988.

Padden, C., Meir, I., Aronoff, M., Sandler, W. The grammar of space in two new sign languages. In: Brentari, D., editor. Sign Languages: A Cambridge Survey. Cambridge, UK: Cambridge Univ. Press; 2010. p. 573-95.

Petitto LA. On the autonomy of language and gesture: evidence from the acquisition of personal pronouns in American Sign Language. Cognition. 1987; 27:1-52. [PubMed: 3691016]

Petitto LA, Holowkab S, Sergioc L, Levy B, Ostry D. Baby hands that move to the rhythm of language: hearing babies acquiring sign languages babble silently on the hands. Cognition. 2004; 93:43-73. [PubMed: 15110725]

Petitto LA, Marentette PF. Babbling in the manual mode: evidence for the ontogeny of language. Science. 1991; 251:1483-96.

Polich, L. The Emergence of the Deaf Community in Nicaragua: "With Sign Language You Can Learn So Much”. Washington, DC: Gallaudet Univ. Press; 2005.

Ravid D, Schiff R. Morphophonological categories of noun plurals in Hebrew. Linguistics. 2009; 47:45-63.

Richie R, Yang C, Coppola M. Modeling the emergence of lexicons in homesign systems. Top Cogn Sci. 2014; 6:183-195. [PubMed: 24482343]

Sandler W, Aronoff M, Meir I, Padden C. The gradual emergence of phonological form in a new language. Nat Lang Linguist Theory. 2011a; 29:503-43. [PubMed: 22223927]

Sandler, W., Lillo-Martin, D. Sign Language and Linguistic Universals. Cambridge, UK: Cambridge Univ. Press; 2006.

Sandler W, Meir I, Dachkovsky S, Padden C, Aronoff M. The emergence of complexity in prosody and syntax. Lingua. 2011b; 121:2014-33. [PubMed: 23087486]

Sandler W, Meir I, Padden C, Aronoff M. The emergence of grammar in a new sign language. PNAS. 2005; 102:2661-65. [PubMed: 15699343]

Sandler, W. Visual prosody. In: Pfau, R.Steinbach, M., Woll, B., editors. Handbook of Sign Language Linguistics. Berlin: Mouton; 2012. p. 55-77.

Schembri A, Jones C, Burnham D. Comparing action gestures and classifier verbs of motion: evidence from Australian Sign Language, Taiwan Sign Language, and nonsigners' gestures without speech. J Deaf Stud Deaf Educ. 2005; 10:272-90. [PubMed: 15858072]

Schick, B. PhD thesis. Purdue Univ; West Lafayette, IN: 1987. The acquisition of classifier predicates in American Sign Language. 
Schlenker, P. Visible meaning: sign language and the foundations of semantics. 2015. Unpubl. ms. http://ling.auf.net/lingbuzz/002447

Senghas A, Coppola M. Children creating language: how Nicaraguan Sign Language acquired a spatial grammar. Psychol Sci. 2001; 12:323-28. [PubMed: 11476100]

Senghas A. Inter-generational influence and ontogenetic development in the emergence of spatial grammar in Nicaraguan Sign Language. Cogn Dev. 2003; 18:511-31.

Singleton JL, Morford JP, Goldin-Meadow S. Once is not enough: standards of well-formedness in manual communication created over three different timespans. Language. 1993; 69:683-715.

So C, Coppola M, Licciardello V, Goldin-Meadow S. The seeds of spatial grammar in the manual modality. Cogn Sci. 2005; 29:1029-43. [PubMed: 21702801]

Stokoe, WC, Jr. Sign Language Structure: An Outline of the Visual Communication Systems of the American Deaf. Buffalo, NY: Univ. Buffalo; 1960.

Stokoe, WC., Jr, Casterline, D., Croneberg, C. A Dictionary of American Sign Language on Linguistic Principles. Silver Spring, MD: Linstok; 1965.

Strickland B, Geraci C, Chemla E, Schlenker P, Kelepir M, Pfau R. Event representations constrain the structure of language: sign language as a window into universally accessible linguistic biases. PNAS. 2015; 112:5968-73. [PubMed: 25918419]

Supalla, T. PhD thesis. Dep. Psychol., Univ. Calif; San Diego: 1982. Structure and acquisition of verbs of motion in American Sign Language; p. 135

Supalla, T., Clarke, P. Sign Language Archeology. Washington, DC: Gallaudet Univ. Press; 2015.

Tomasello, M. Origins of Human Communication. Cambridge, MA: MIT Press; 2008.

Volterra, V. Gestures, signs and words at two years, or when does communication become language?. In: Kyle, J., Woll, B., editors. Language in Sign. London: Croom Helm; 1983. p. 109-15.

Volterra, V. From single communicative signal to linguistic combinations in hearing and deaf children. In: Montangero, J.Tryphon, A., Dionet, S., editors. Symbolisme et connaissance [Symbolism and Knowledge]. Geneva: Fond. Arch. Jean Piaget; 1987. p. 89-106.

Volterra, V., Iverson, JM. When do modality factors affect the course of language acquisition?. In: Emmorey, K., Reilly, J., editors. Language, Gesture, and Space. Hillsdale, NJ: Erlbaum; 1995. p. 371-90.

Wedel, A. PhD thesis. Dep. Psychol., Univ. Calif; San Diego: 2004. Self-organization and categorical behavior in phonology; p. 248

Zwitserlood, I. Classifying Hand Configurations in Nederlandse Gebarentaal [Sign Language of the Netherlands]. Utrecht, Neth: LOT; 2003.

Zwitserlood, I. Classifiers. In: Pfau, R.Steinbach, M., Woll, B., editors. Handbook of Sign Language Linguistics. Berlin: Mouton; 2012. p. 158-86. 

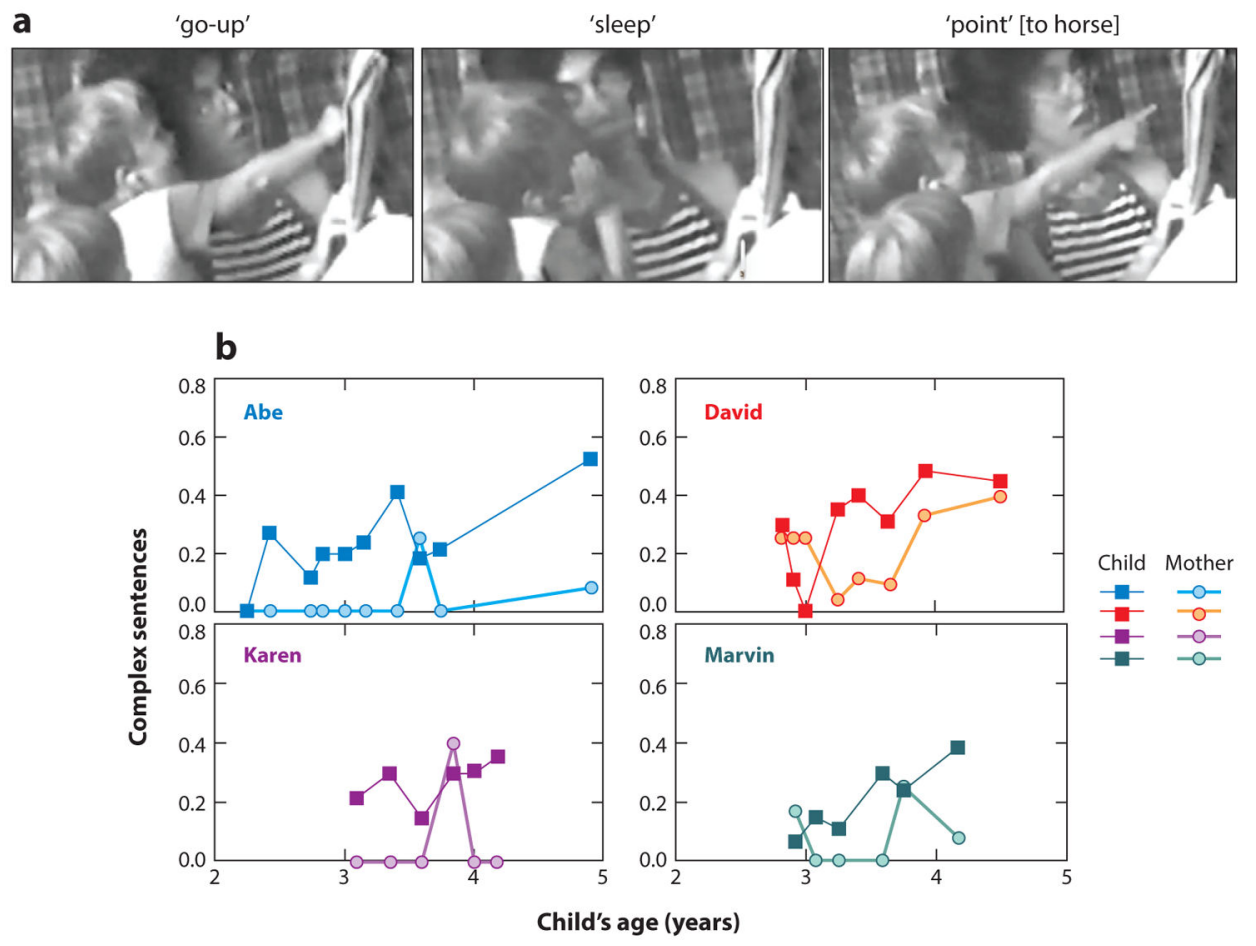

Figure 1.

Complex sign sentences in homesign. (a) An example of a complex sentence produced by an American homesigner describing a picture of a horse who is sleeping on top of a house: 'goup' [hand moves up] — 'sleep' [hand held on cheek]—'point to horse' [in picture]. (b) The number of complex sign sentences used by four American homesigners and their hearing mothers at a particular point in time, as a proportion of the total sign sentences the child (squares) or mother (circles) produced at that time point. Panel $b$ modified from figure 3 of Goldin-Meadow \& Mylander (1998). 


\section{[['coin' [point to coin][point to self]] versus [['coin' point to self]]}
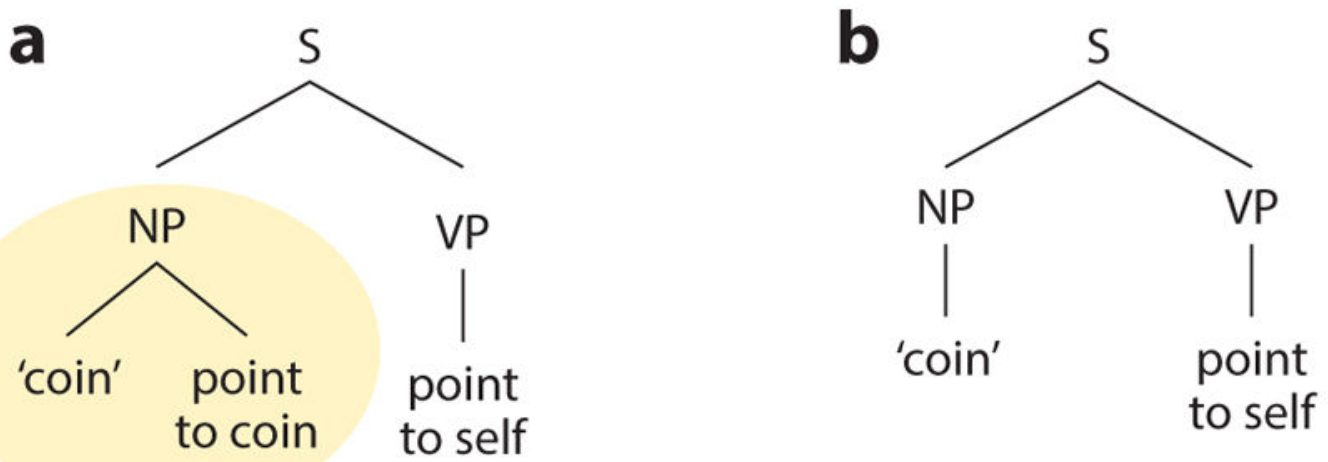

Figure 2.

(a) A sign sentence produced by an American child homesigner with hierarchical structure, in particular, with branching in the noun phrase (NP) (yellow circle). (b) A sign sentence produced by the same child without hierarchical structure. 
a

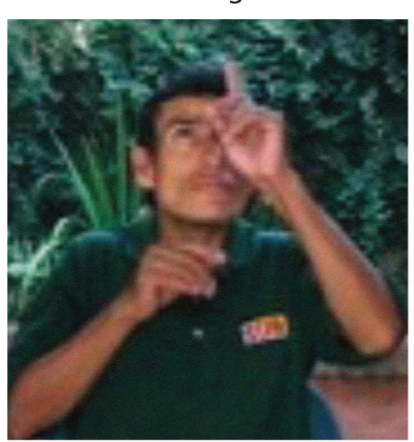

- Locative deictics (points to empty space referring to locations)

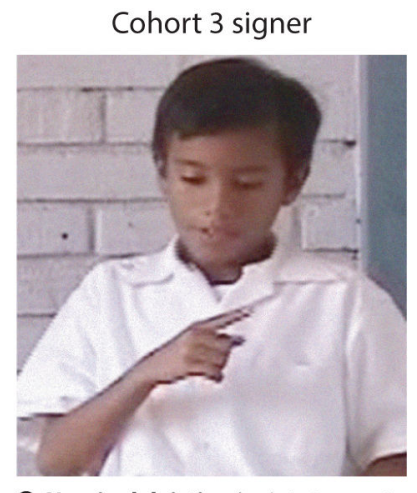

O Nominal deictics (points to empty space referring to characters)

\section{b}

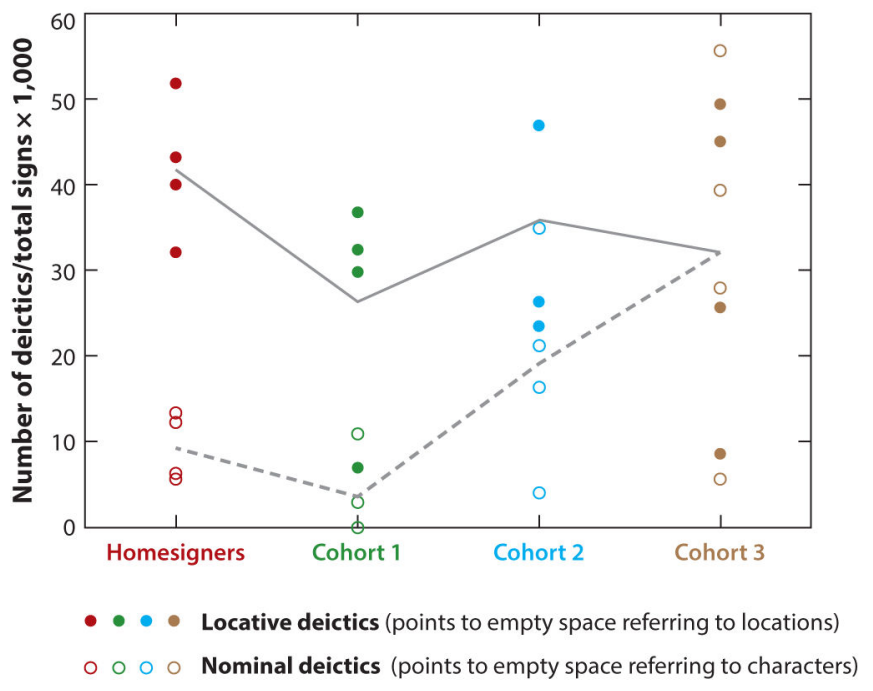

Figure 3.

(a) Locative versus nominal deictics in a Nicaraguan adult homesigner and a Cohort 3 signer of Nicaraguan Sign Language (NSL). (b) Locative and nominal deictics in homesigners and Cohort 1, 2, and 3 signers of NSL. Filled circles represent locative uses (solid line indicates the mean), and open circles represent nominal uses (dashed line indicates the mean). In contrast to locative points, which do not differ systematically across groups, nominal points exhibit a linear increase across Cohorts 1, 2, and 3 (and no difference between homesigners and Cohort 1), suggesting the emergence of a new function for this form when the sign system is transmitted to a new cohort. Modified with permission from Coppola \& Senghas (2010). 
No-agent vignette
a ingle pen is upright on tab

Nominal handshape Predicate handshape
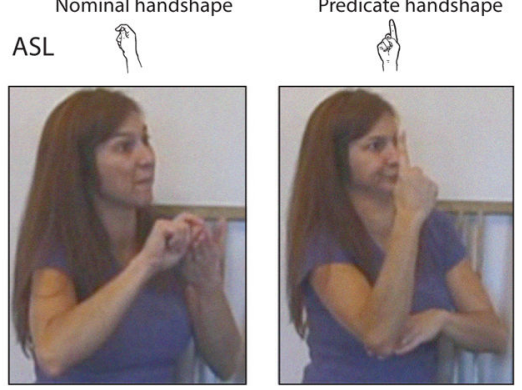
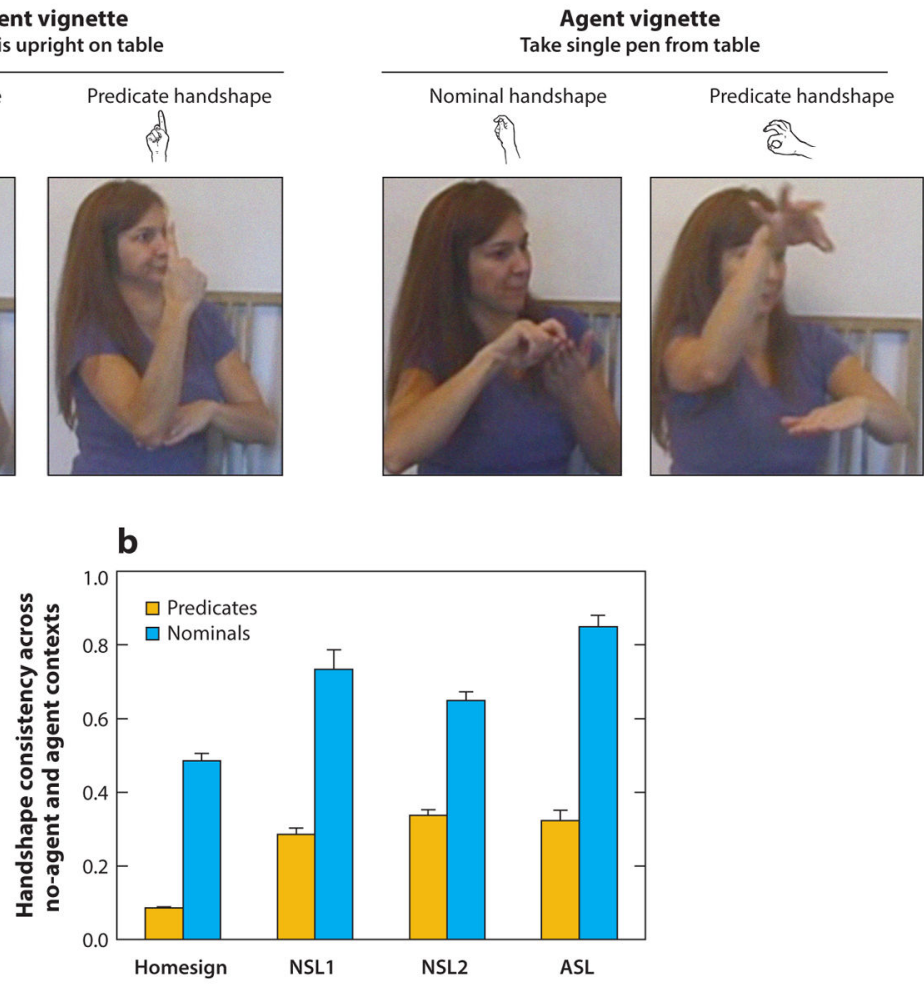

Figure 4.

(a) Examples of the handshapes used by an American Sign Language (ASL) signer in the nominal and predicate signs she produced to describe a pen in an agent context and in a noagent context. (b) The proportion of handshapes that appeared in both agent and no-agent contexts in nominal versus predicate signs produced by homesigners, Nicaraguan Sign Language (NSL) Cohort 1 signers, an NSL Cohort 2 signer, and ASL signers. Modified from figures 3 and 4 of Goldin-Meadow et al. (2015a). 
a Morphological class A (not a phonological class)

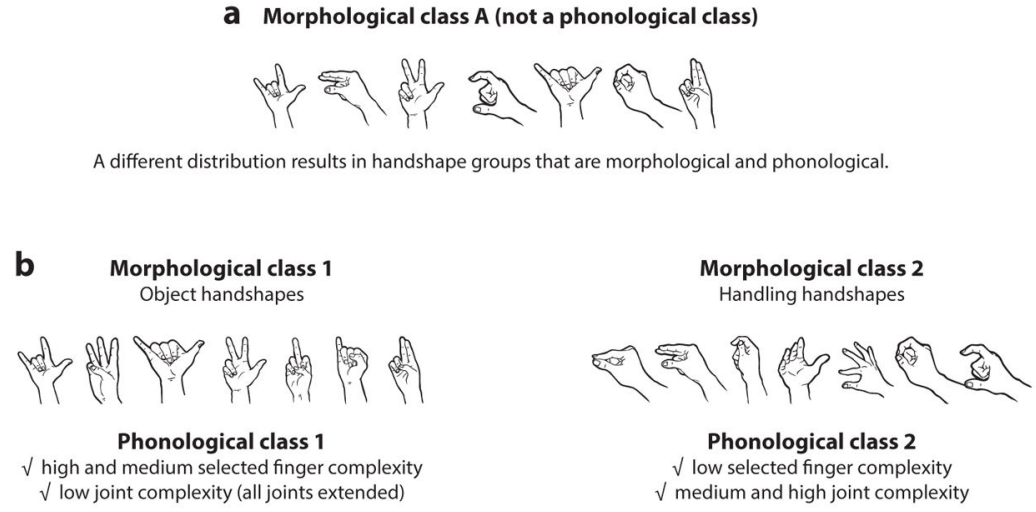

Figure 5.

(a) A hypothetical grouping of handshapes that constitutes a morphological class but not a phonological class. (b) Two hypothetical groupings of handshapes, each of which constitutes both a morphological and a phonological class. The class 1 handshapes on the left are object handshapes (a morphological distinction), all of which have high finger complexity and low joint complexity (phonological distinctions). The class 2 handshapes on the right are handling handshapes (a morphological distinction), all of which have high joint complexity and low finger complexity (phonological distinctions). Modified from figure 3 of Coppola $\&$ Brentari (2014). 


\section{Table 1}

The resilient properties of language as instantiated in deaf children's homesign systems ${ }^{a}$

\begin{tabular}{|c|c|}
\hline \multicolumn{2}{|l|}{ Words } \\
\hline Stability & Sign forms are stable and do not change capriciously with changing situations \\
\hline Paradigms & Signs consist of smaller parts that can be recombined to produce new signs with different meanings \\
\hline Categories & The parts of signs are composed of a limited set of forms, each associated with a particular meaning \\
\hline Arbitrariness & Pairings between sign forms and meanings can have arbitrary aspects, albeit within an iconic framework \\
\hline Grammatical functions & Signs are differentiated by the noun, verb, and adjective grammatical functions they serve \\
\hline Words for relational concepts & Particular signs are used to signal past, future, and uncertainty and to mark illocutionary force \\
\hline \multicolumn{2}{|l|}{ Sentences } \\
\hline Underlying frames & Predicate frames underlie sign sentences \\
\hline Deletion & Consistent production and deletion of signs within a sentence mark particular thematic roles \\
\hline Word order & Consistent orderings of signs within a sentence mark particular thematic roles \\
\hline Inflections & Consistent inflections on signs mark particular thematic roles \\
\hline Hierarchical structure & Complex nominal constituents can be embedded within larger sign sentences \\
\hline Recursion & Complex sign sentences containing more than one proposition are created by recursion \\
\hline Redundancy reduction & Redundancy is systematically reduced in the surface of complex sign sentences \\
\hline \multicolumn{2}{|l|}{ Language use } \\
\hline Here-and-now talk & Signs are used to make requests, comments, and queries about the present \\
\hline Displaced talk & Signs are used to communicate about the past, future, and hypothetical \\
\hline Generics & Signs are used to make generic statements, particularly about animals \\
\hline Narrative & Signs are used to tell stories about self and others \\
\hline Self-talk & Signs are used to communicate with oneself \\
\hline Metalanguage & Signs are used to refer to one's own and others' signs \\
\hline
\end{tabular}

Annu Rev Linguist. Author manuscript; available in PMC 2018 January 01. 


\section{Table 2}

Environmental factors identified as crucial for a fully established language and the populations in which they are manifest

\begin{tabular}{l|c|c|c}
\hline & Homesign & NSL Cohort 1 & NSL Cohort 2 \\
\hline Is the system the primary means of communication? & Yes & Yes & Yes \\
\hline Is a linguistic community present? & No & Yes & Yes \\
\hline Is a language model present? & No & No & Yes \\
\hline
\end{tabular}

